\title{
New remains attributable to the holotype of the sauropod dinosaur Neuquensaurus australis, with implications for saltasaurine systematics
}

\author{
Michael D. D'Emic and Jeffrey A. Wilson \\ Acta Palaeontologica Polonica 56 (1), 2011: 61-73 doi: http://dx.doi.org/10.4202/app.2009.0149
}

The Late Cretaceous South American sauropods Neuquensaurus australis and Saltasaurus loricatus are represented by well-preserved and abundant material that has been integral to our understanding of titanosaur anatomy for decades. Although the hypodigms for these species span most of the skeleton, holotypic materials are limited to a few bones that do not overlap between the two taxa. In this contribution, we augment the holotype of Neuquensaurus australis with a partial sacrum that was preserved in articulation with one of the caudal vertebrae from its original description, but not recognised as such at the time. We document this field association via the presence of a broken piece of matrix on the sixth sacral vertebral centrum that has a snap-fit to matrix on the rim of the anterior condyle of the holotypic biconvex vertebra. Based on comparisons with a more complete sacrum and ilium of a referred specimen of Neuquensaurus australis, we interpret this biconvex vertebra to be the seventh sacral vertebra. This raises the possibility that the biconvex "first caudal" vertebra of some other titanosaurs may be part of the sacrum as well. Augmentation of the Neuquensaurus australis holotype to include a sacrum makes it directly comparable to the holotype of Saltasaurus loricatus. Morphological differences in the number, shape, and proportion of sacral vertebrae allow discrimination between Neuquensaurus and Saltasaurus, confirming their generic separation. The El Brete quarry, which preserves the holotypic sacrum and abundant referred specimens of Saltasaurus loricatus, also preserves a sacrum consisting of seven vertebrae that bears autapomorphies of Neuquensaurus australis, indicating that these two saltasaurines coexisted.

Key words: Dinosauria, Sauropoda, Titanosauria, Neuquensaurus, Saltasaurus, taxonomy, Cretaceous, South America.

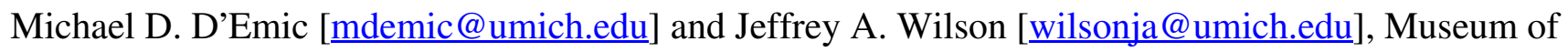
Paleontology and Department of Geological Sciences, The University of Michigan, 1109 Geddes Avenue, Ann Arbor, Michigan 48109-1079, USA. 
This is an open-access article distributed under the terms of the Creative Commons Attribution License (for details please see creativecommons.org), which permits unrestricted use, distribution, and reproduction in any medium, provided the original author and source are credited.

Farif Full text $(502.7 \mathrm{kB})$ 